\title{
SERVICE BLUEPRINTING AND DISCRETE SIMULATION IN HOSPITALITY PRACTICE (CASE STUDY)
}

\author{
[Service Blueprinting a diskrétní simulace v pohostinství v praxi \\ (př́ípadová studie)]

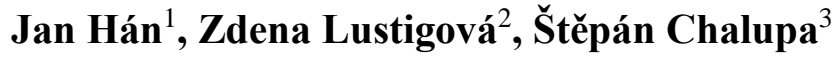 \\ ${ }^{1}$ The Institute of Hospitality Management in Prague, Svídnická 506, 18100 Prague 8 \\ Email: han@vsh.cz \\ ${ }^{2}$ The Institute of Hospitality Management in Prague, Svídnická 506, 18100 Prague 8 \\ Email: lustigova@vsh.cz \\ ${ }^{3}$ The Institute of Hospitality Management in Prague, Svídnická 506, 18100 Prague 8 \\ Email: chalupa@vsh.cz.
}

\begin{abstract}
Business process modeling and simulation have become a central aspect of the way businesses understand, support, and communicate about their processes. Frequent prominent approaches this paper deals with are 1/service blueprinting, 2/business process modeling notation (BPMN) and 3/ discrete-event simulation (DES), which might be generally event oriented, activity oriented and process oriented. The use of these approaches in the area of hospitality is still very rare. The authors present the issue, solutions and selected results, obtained from the case study, implemented in Prague, in the4-star hotel in 2015.
\end{abstract}

Keywords: hotel, modelling, service, simulation.

JEL classification: M00

Doručeno redakci: 28.4.2016; Recenzováno: 10.5.2016; 17.5.2016; Schváleno k publikování: 19.10.2016

\section{Introduction}

Business process modeling and simulation have become a central aspect of the way businesses understand, support, and communicate about their processes. Frequent prominent approaches this paper deals with are 1/service blueprinting, 2/business process modeling notation (BPMN) and 3/ discrete-event simulation (DES), which might be generally event oriented, activity oriented and process oriented.

According to Kazemzadeh, Milton \& Johnson (2015) service blueprinting supports customer service processes whilst BPMN helps understand a firm's processes with a particular focus on how information and communications technology support processes, as well as on process automation. 
Figure 1: Service Blueprint - Hotel Stay (fictive theoretical example)

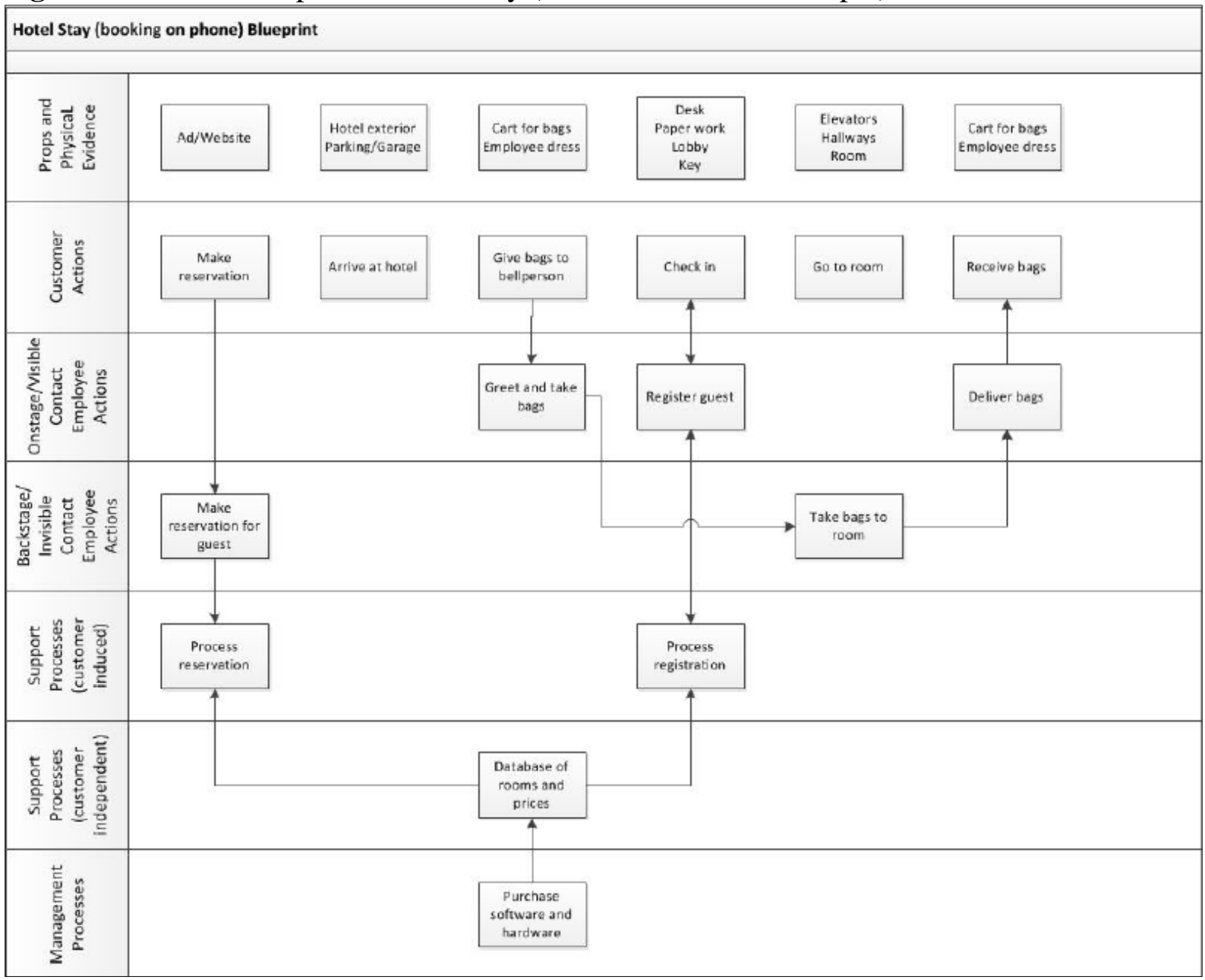

Source: Researchgate.com: Service Blueprint example - Hotel Stay [online] [cit. 28th January 2016]. Accessible from: www.researchgate.net/figure/277363901_fig1_Figure-2-Service-Blueprint-example-Hotel-Stay

Figure 2: Service blueprint of Grand Hilton Hotel

\section{Service Blueprint of Grand Hilton Hotel}

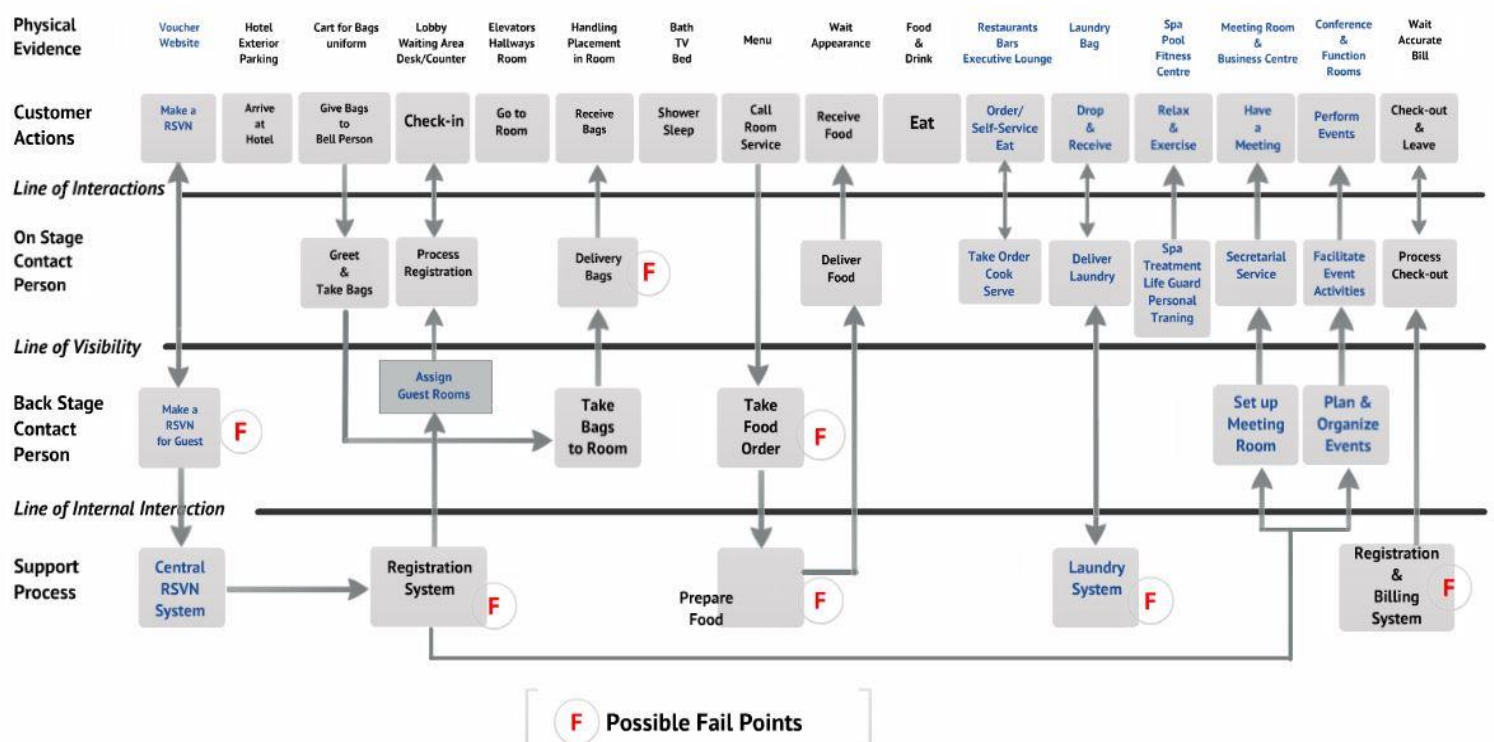

Source: Prezi.com: Copy of Hilton Service Blueprint [online] [cit. 28th January 2016]. Available at: https://prezi.com/xvkv4kipzjtf/copy-of-hilton-service-blueprint/ 
Simulation (in both BPMN and DES understanding) is a component of a business rules engine. It might be a solution to both off-line design and on-line operational management problems. Researchers derive rules from the experts' mental models; they provide for process operation and making decisions that will facilitate forecasting along with a change that might impact those decisions. Formalizing and simulating these models makes the automation of business rules more robust. In the design of new business rules, simulation provides a way to validate that processes will work as designed.

To define, measure, analyze, improve, and control the processes is not an easy task and it depends on the earnest participation and responsibility of everyone involved. In particular, the last three (analyze, improve \& control) revolve around the identification of root causes, and putting controls in place to keep quality high. According to Barnet 2003 "clearly, simulation can play the important role of reducing the risk of change and managing change".

A discrete-event simulation (DES) is defined by Wikipedia as a tool, modeling the operation of a system as a discrete sequence of events in time. Each event occurs at a particular instant in time and marks a change of state in the system (Robinson 2004). Between consecutive events, no change in the system is assumed to occur; thus the simulation can directly jump in time from one event to the next.

This contrasts with continuous simulation in which the simulation continuously tracks the system dynamics over time. Instead of beingevent-based, this is called an activity-based simulation; time is broken up into small time slices and the system state is updated according to the set of activities happening in the time slice (Matloff 2008).

Since discrete-event simulations do not have to simulate every time slice, they can typically run much faster than the corresponding continuous simulation. In practice simulation is used besides to study the behaviour of various social, economic, ecological or physical systems (especially continuous simulation like BPMN) or to study and optimize various production, logistics or service based systems and their bottle necks/problems/gaps/etc. (especially DES). Simulation is the welcomed method within the decision making processes related e.g. to:

- Optimal and effective sources utilization;

- Elimination of systems bottlenecks;

- Prediction of various systems values development.

The application of simulation is not only in possession of basic and applied research, its application is a perspective in common decision making and predictive tasks and training too. Although the above described features of computer simulation might be very useful for tourism and the area of hospitality, the real application is still very rare. The authors of the innovative paper, published in 2003 at Cornell University [4], mentioned 3 main reasons for using these methods while studying systems in hospitality. These are:

- The system has one or more interdependent, random variables;

- The system dynamics is extremely complex;

- The objective is to observe system behavior over a period of time.

In the text part we will present the possibilities of modeling and simulation tools and methods in the hospitality sector. We focused especially on accommodation and gastronomic services with the goal to support decision making process and to optimize existing work process flows and setups. 
Business systems are controlled systems involving both quantitatively expressed and unexpressed properties and states. These systems evince the certain level of vagueness and uncertainty. This level is done besides by the human factor and its behavior too. From this point of view, the modeling and simulation of these systems are more difficult, the models do not correspond to the real systems exactly and the simulation outputs may not to be $100 \%$ truthful. The level of the verity of simulation experiments outputs is determined specifically by the level of the model's resemblance with the real system and by the adjusted simulation initial conditions and algorithms.

According to Han, Lustigova, Chalupa (2015) simulation experiments can provide sufficient answers to the large set of questions "What happens, if we change/shorten/limit/cancel......?". In the real systems of accommodation and related services providing simulation experiments there is a great application potential in the following subsystems and processes:

- front office (check in, check out, personal services related to that),

- housekeeping,

- laundry cleaning,

- storage and logistics,

- wellness and fitness services etc.

Within gastronomy services the big potential of the simulation tools and application methods can be found in the following subsystems and processes:

- restaurant service,

- material storage and logistics etc.

Within the business planning and decision making processes the following types of values are monitored:

- exploitation of particular resources (especially human resources) and equipment,

- time duration of particular processes,

- number of processed and un processed units (clients, cars etc.),

- length of units' queues etc.

Thanks to variant sets of data resulting from simulation experiments there is possible to identify the relationships and coherence between particular conditions and situations in a model and consequently in a real system.

\section{Case study 1: business process redesign}

\section{Problems description}

Simulation experiments can support the decision making process within the business processes and jobs redesign. A typical situation of that is making the organizational structure slimmer or the process of jobs reduction (dismissals). Simulation can help to answer the question "What is the result of the specific jobs and processes redesign?", "Where are the risks and threats?".

The simulation team at the Institute of Hospitality Management in Prague in the framework of this type of tasks received the following assignment from the middle sized hotel in Prague. The strategic plan of the hotel reduces the operation of the hotel restaurant to the breakfast mode only. Within lunch and dinner, the meal will be arranged by the person doing simultaneously another job in the hotel in the form of delivery and service of externally prepared food. Is it real to put this job rearrangement into practice without the reduction of quality of both existing and new services? 


\section{Methods and results}

The model of relevant existing hotel subsystems was created within the special simulation tool. Tecnomatix Plant Simulation software by Siemens was used to model the particular hotel processes. The software is focused chiefly on the modeling and simulation of discrete systems. Within the implementation in the hospitality sector by the simulation team at the Institute of Hospitality Management in Prague the software proved the suitability of usage in the sector of this type of services.

At first the analysis of the particular processes was made with the help of the hotel management. The description of particular processes contained the data about activities, responsibilities, resources, times, inputs, outputs, priorities etc. Most of these data were described with the help of statistics and probability functions and tools.

The issues of the analysis provided the base for the mental model creation. This mental model was formalized by the common tools of process modeling and representation. The hotel management agreed and slightly modified the issues of the processes analysis. After that the computer model of the existing subsystems and processes was created with the help of the mentioned modeling software. The graphical representation of the model is depicted in the picture.

Figure 3: Graphical representation of the hotel subsystem model

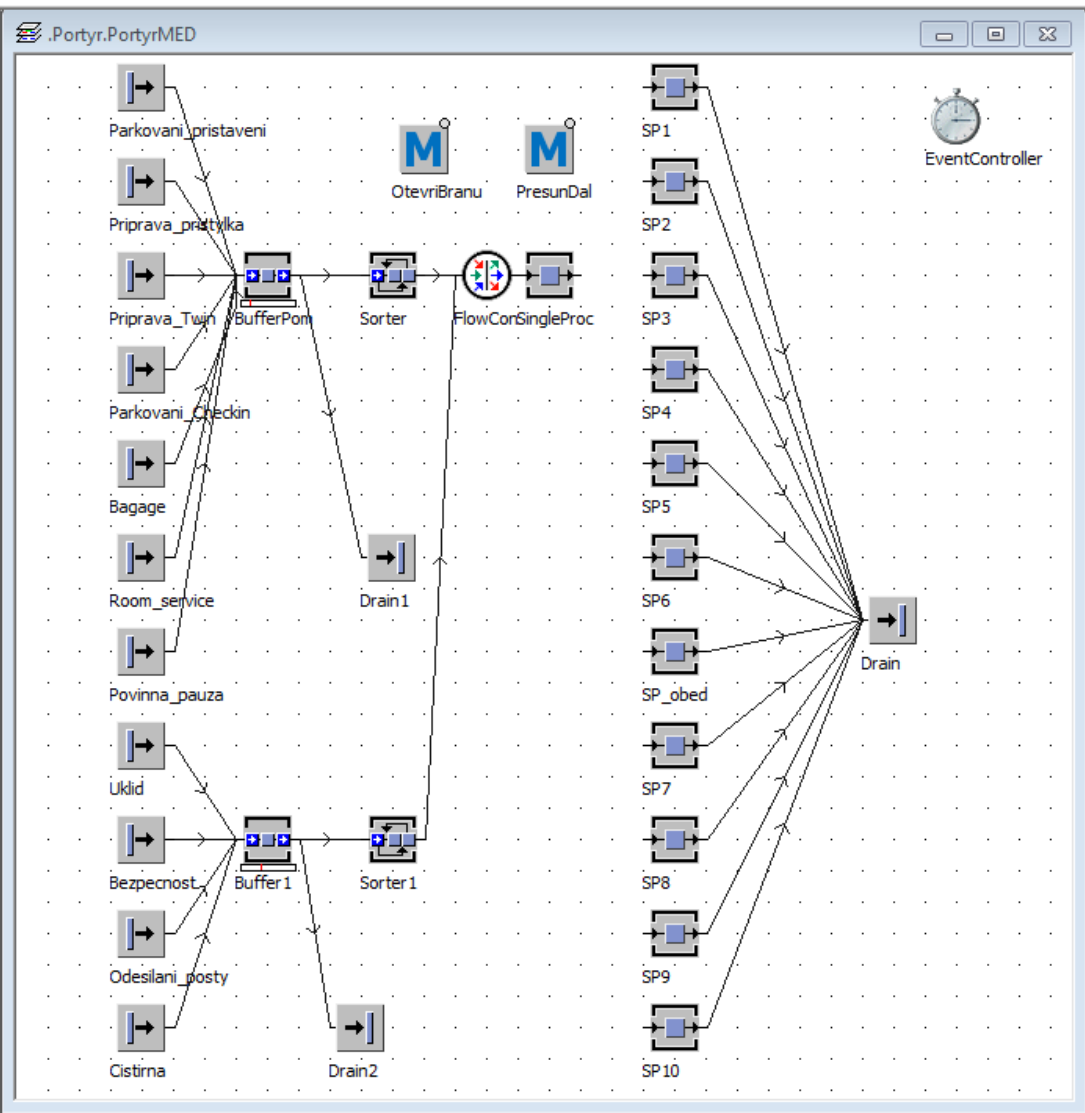

Source: Own elaboration

The "current state of art" (CSA) model was validated by simulation experiments based on the sets of real business data. The data issued from experiments were compared with the data measured in the real system. 
Than the validated CSA model was modified according to the requirements of the project assignment. New processes were added, job tasks were redesigned etc. The model was prepared for simulation experiments related to the new possible variant arrangements of the hotel processes.

Simulation experiments were done while respecting large sets of conditions. The results, particularly the data about processing times, the level of resources utilization, lengths of unit queues, numbers of served units etc. were gathered and analysed. The results of experiments were presented to the hotel management in a well arranged form together with the possibility of particular experiments of computer animation. The mentioned simulation software is able to graphically animate simulated processes in the 2D and 3D mode.

\section{Selected results:}

One of our outputs, concerning the job tasks and setups for a porter, is presented in a form of the final performance statistics below.

Table 1: Selected results of model simulation

\begin{tabular}{|l|l|l|l|l|l|l|}
\hline \multicolumn{2}{|l}{ Low occupation level - simulation time 11:55:26 } \\
\hline Activity & $\begin{array}{l}\text { The } \\
\text { number } \\
\text { of task } \\
\text { processed }\end{array}$ & $\begin{array}{l}\text { The relative } \\
\text { number of } \\
\text { processed } \\
\text { tasks }\end{array}$ & $\begin{array}{l}\text { Total } \\
\text { time } \\
\text { consumed } \\
\text { by } \\
\text { activity }\end{array}$ & $\begin{array}{l}\text { Average } \\
\text { time to } \\
\text { process } \\
\text { task }\end{array}$ & $\begin{array}{l}\text { Used } \\
\text { simulation } \\
\text { process } \\
\text { time }\end{array}$ & $\begin{array}{l}\text { Total } \\
\text { number of } \\
\text { unprocessed } \\
\text { units }\end{array}$ \\
\hline $\begin{array}{l}\text { Parking- } \\
\text { Check-in }\end{array}$ & 3 & $7 \%$ & $1: 03: 23$ & $0: 21: 07$ & $9 \%$ & - \\
\hline $\begin{array}{l}\text { Adding } \\
\text { Extra bed }\end{array}$ & 4 & $10 \%$ & $1: 15: 52$ & $0: 18: 58$ & $11 \%$ & - \\
\hline $\begin{array}{l}\text { Preparing } \\
\text { Twin room }\end{array}$ & 2 & $5 \%$ & $0: 40: 00$ & $0: 20: 00$ & $6 \%$ & - \\
\hline $\begin{array}{l}\text { Delivery } \\
\text { Check-out }\end{array}$ & 4 & $10 \%$ & $1: 21: 10$ & $0: 20: 39$ & $11 \%$ & 1 \\
\hline $\begin{array}{l}\text { Baggage } \\
\text { care }\end{array}$ & 10 & $24 \%$ & $0: 59: 56$ & $0: 05: 59$ & $8 \%$ & - \\
\hline $\begin{array}{l}\text { Room } \\
\text { service }\end{array}$ & 2 & $5 \%$ & $0: 40: 01$ & $0: 20: 00$ & $6 \%$ & - \\
\hline Clean-up & 2 & $5 \%$ & $0: 23: 59$ & $0: 11: 59$ & $3 \%$ & - \\
\hline $\begin{array}{l}\text { Security } \\
\text { activity }\end{array}$ & 6 & $14 \%$ & $2: 01: 47$ & $0: 20: 17$ & $17 \%$ & - \\
\hline Post service & 1 & $2 \%$ & $0: 11: 13$ & $0: 11: 13$ & $2 \%$ & - \\
\hline Laundry & 1 & $2 \%$ & $0: 46: 57$ & $0: 46: 57$ & $7 \%$ & 1 \\
\hline Break (law) & 1 & $2 \%$ & $0: 30: 00$ & $0: 30: 00$ & $4 \%$ & - \\
\hline $\begin{array}{l}\text { Delivery } \\
\text { stay }\end{array}$ & 3 & $7 \%$ & $1: 03: 40$ & $0: 21: 13$ & $9 \%$ & - \\
\hline $\begin{array}{l}\text { Delivery } \\
\text { parking }\end{array}$ & 3 & $7 \%$ & $0: 59: 16$ & $0: 19: 45$ & $8 \%$ & - \\
\hline Total & $\mathbf{4 2}$ & $\mathbf{1 0 0 \%}$ & $\mathbf{1 1 : 5 7 : 1 4}$ & & $\mathbf{1 0 0 \%}$ & $\mathbf{2}$ \\
\hline
\end{tabular}

Source: Own elaboration 
According to these results the porter is completely occupied and needs help with unprocessed units (2, see last column). This fact was confirmed by a Front Office Manager. By adding food service processes, the total number of unprocessed units and tasks increased to 6, which is unacceptable.

This computer simulation showed clearly that additional porter responsibilities could negatively influence the current quality of service, by increasing the number of unprocessed tasks.

The following charts clearly identify the most time consuming activities within the low occupation level. Similar graphs for the high occupation level present a significant decrease of relative time devoted to certain activities, like security, while others significantly increased.

Figure 3: The most time consuming activities within the low occupation level.

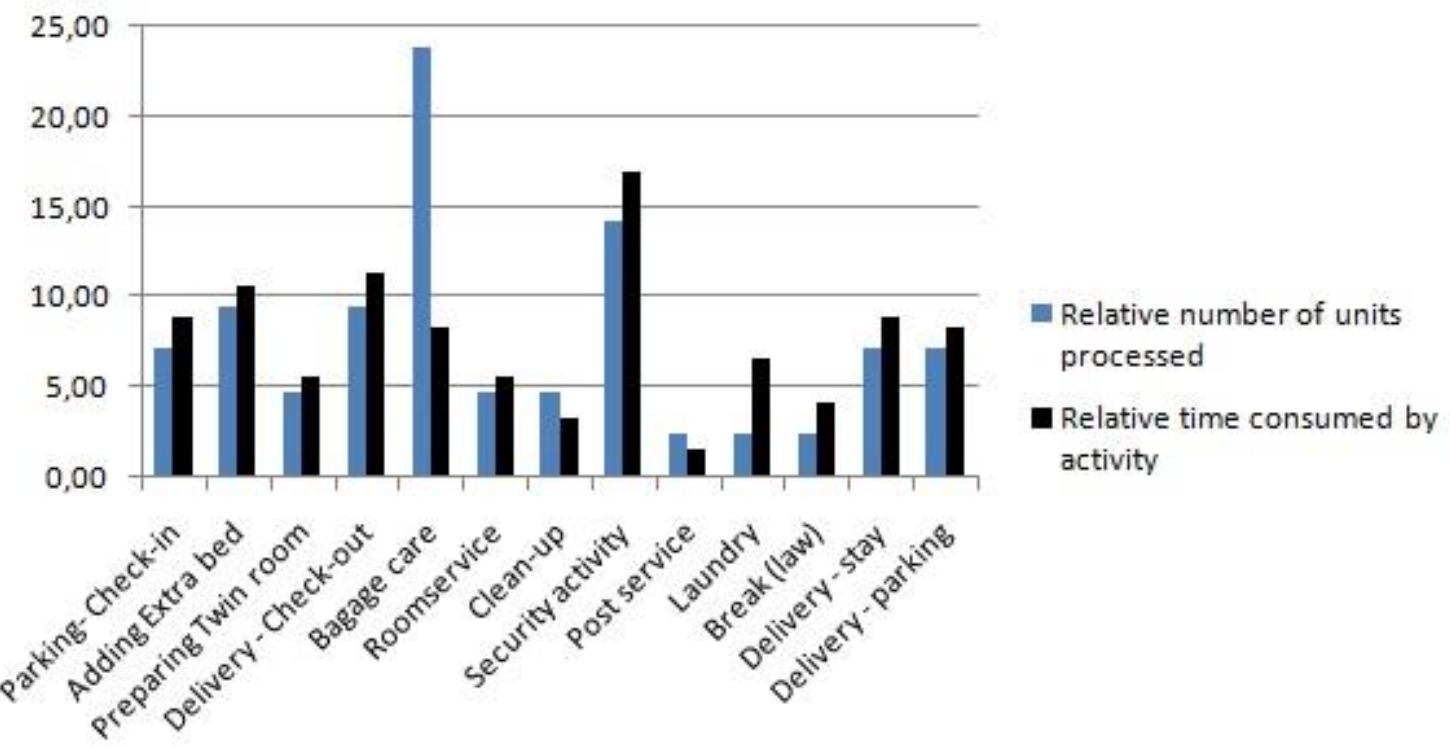

Source: Own elaboration

This computer simulation showed clearly that additional porter responsibilities could negatively influence the current quality of service, by increasing the number of unprocessed tasks.

Note: It is necessary to understand that the importance of different processes was weighted, the seasons and different periods of the day were respected, and the proper distribution functions for the description of different tasks were selected. All of the above mentioned was proposed, verified and finally selected or refused on the base of experts' analysis and a deep discussions with the Front Office Manager and the Director of the hotel. Several types of simulation experiments were proposed, prepared and formalized according to the needs.

\section{Evaluation and implementation}

The hotel management representatives have proposed on the base of the analysis of simulation results another type of experiments modifying the values of priorities of particular business processes in the model to assure of the optimization of processes. Another set of simulation experiments was done quickly (till next day) and the results were analyzed and presented. 
The analysis of experiments results showed the unfeasibility of some intended processes and jobs redesign realization due to the conspicuous reduction of provided services quality. Intended changes strongly reduced the level of personal costs (jobs reduction) and showed an increased number of unserved units (clients), longer queues etc.

Simulation issues were respected by the hotel decision making process and new processes were designed with respect to them.

\section{Conclusion}

The case study revealed only one small and very limited example of simulation methods and application of tools. Its application potential in the research and practical decision making process in the hospitality and tourism industry is significantly broader and deeper.

However, its application has several limitations. Two groups of limitations are the most important in relation to the above mentioned type of tasks.

Accuracy of a simulation model:

The level of similarity of the simulation model with the real system determines significantly both the validity and the applicability of simulation results. The systems like business systems contain as mentioned above the certain level of uncertainty and vagueness. The usage of mathematical methods and tools related to the probability and statistics solves this issue to some extent. The extent and thoroughness of initial analyses are the most important from this point of view. In addition to that the possibilities of modelling and simulation tools (software) are crucial too. Its tools compel the model maker to make the model much simpler and limited in relation to the real system.

Condition-settings of initial simulation experiments:

Results of simulation experiments depends on the initial conditions of a particular simulation run too. The initial number of resources, queues limitations, used probabilistic distribution functions of units' arrival and particular processing times, values of processes priorities, length of simulation runs etc. they are important for the final results of particular simulation experiments. The careful analysis of these types of data and their verification in the case of the model with the help of variant settings is needed. It is rewarding to verify these conditions with the person experienced with the real system adequately.

The successful interpretation of the results of simulation experiments requires some understanding of relationships among generated data. For these purposes more experiments with the different settings of the model can be beneficial. That is the base for the successful answer to the question: "What happens, if ...?".

\section{References}

[1] BARNETT, M. W., 2003. Modelling and simulation at business process management [online]. 1. March 2015 [published 2013] Available at: www.bptrends.com/publicationfiles/11-03\%20WP\%20Mod\%20Simulation\%20of\% 20BPM\%20-\%20Barnett-1.pdf.

[2] CAMILLO, A. A., 2015. Handbook of Research on Global Hospitality and Tourism Management. Woodbury University, USA: IGI Global. ISBN 9781466686076. 
[3] DOUGLAS, W., 1986. Jones, Empirical Comparison of Priority Queue and Event Set Implementations. Magazine Communications of the ACM, 29(4), 300-311.

[4] FISHMAN, G. S, 2001. Discrete-event simulation: modeling, programming and analysis. New York: Springer. ISBN 978-4419-2892-4.

[5] GONZALES, S., 2013. Copy of Hilton Service Blueprint [online]. Available at: https://prezi.com/xvkv4kipzjtf/copy-of-hilton-service-blueprint/.

[6] HÁN, J., Z. LUSTIGOVÁ and Š. CHALUPA, 2015. System Modelling and Simulation in Hospitality Practice (Case Study). Praha: VŠH, s. 69-79. ISBN 978-80-87411-70-4.

[7] KAZAMZADEH, Y., S. K. MILTON and L. W. JOHNSON, 2015. Service Blueprinting and Business Process Modeling Notation (BPMN): A Conceptual Comparison. Asian Social Science, 11(12). ISSN 1911-2017.

[8] LAW, M. A., 2014. Simulation Modeling and Analysis. 5th edition. Mcgraw-Hill. ISBN 978-0073401324.

[9] MATLOFF, N., 2014. Introduction to Discrete-Event Simulation and the SimPy Language [online]. Available at: http://heather.cs.ucdavis.edu/ matloff/ 156/PLN/DESimIntro.pdf

[10] ROBINSON, S., 2004. Simulation - The practice of model development and use. England: Wiley. ISBN 0-470-84772-7.

[11] THOMPSON, G. and R. VERMA, 2003. Computer simulation in hospitality teaching, practice, and research. Cornell Hotel and Restaurant Administration Quarterly, 44(2), 85-92. ISSN 1938-9663. 